(2) Open Access Full Text Article

ORIGINAL RESEARCH

\title{
Diabetic Foot Self-Care Practices Among Adult Diabetic Patients: A Descriptive Cross-Sectional Study
}

This article was published in the following Dove Press journal:

Diabetes, Metabolic Syndrome and Obesity: Targets and Therapy

\author{
Namo Hirpha' \\ Ramanjireddy Tatiparthi ${ }^{2}$ \\ Temesgen Mulugeta $\mathbb{( D}^{3}$ \\ 'Department Hospital Pharmacy, Bako \\ Primary Hospital, West Shewa, Oromia, \\ Ethiopia; ${ }^{2}$ Institute of Health, School of \\ Pharmacy, Department of Pharmaceutics, \\ Jimma University, Jimma, Oromia, \\ Ethiopia; ${ }^{3}$ Institute of Health, School of \\ Pharmacy, Department of Clinical \\ Pharmacy, Jimma University, Jimma, \\ Oromia, Ethiopia
}

Background: Adequate foot care and regular foot examinations along with optimal glycemic control are effective strategies to prevent foot ulceration.

Aim: The aim of this study was to describe the patterns of foot self-care practice among diabetic patients attending an ambulatory clinic.

Methods: A descriptive cross-sectional study was conducted at the ambulatory clinic of Jimma Medical Center. A consecutive sampling technique was used. The data were analyzed by SPSS version 20 and descriptive statistics were used to describe the findings.

Results: A total of 370 diabetic patients (55.9\% male and $68.4 \%$ type 2$)$ were interviewed. The mean $( \pm \mathrm{SD})$ age of the patients was $46.47 \pm 13.63$ years. Over one-third $(35.7 \%)$ of the patients had a previous history of foot ulcer. The majority of the patients self-inspect $(92.5 \%)$ and wash $(82.7 \%)$ their foot at least daily, respectively. In this study, $12.2 \%$ of the patients never inspected the inside of their footwear before putting them on and $42.4 \%$ of the patients never dry between their toes after washing. Most (63.5\%) of patients never used moisturizing creams to lubricate the dry skin. In this study, $23.0 \%$ and $27.6 \%$ of the patients walk in sandals/slippers and in shoes without socks most of the time, respectively. Only $27.3 \%$ of the patients changed their socks daily. Majority (78.4\% and $86.5 \%$ ) of the patients never walk barefoot around and outside their house, respectively, and $75.1 \%$ of the patients never put their feet near the fire.

Conclusion: Diabetic patients were not adequately self-inspect and wash their foot at least daily, dry after wash and moisturize the dry skin. They walk barefoot, in sandals/slippers, and in shoes without socks. Therefore, clinicians should counsel every diabetic patient about the importance of foot self-inspection, foot hygiene, and the risk of walking barefoot, wearing sandals/slippers, and shoes without socks at every follow-up visit.

Keywords: diabetes mellitus, foot self-care, practice, Jimma Medical Center

\section{Background}

Diabetes is a complex, chronic illness requiring continuous medical care with multifactorial risk-reduction strategies beyond glycemic control. ${ }^{1}$ Foot ulceration is a major complication of diabetes mellitus and is associated with high levels of morbidity and mortality, as well as significant financial costs. The lifetime incidence rate of diabetic foot ulceration is $19-34 \%$, with a yearly incidence rate of $2 \%$. After successful healing, the recurrence rates of diabetic foot ulcers (DFU) are $40 \%$ within a year and $65 \%$ within 3 years. $^{2}$

Poor diabetic foot care increases the risk of ulceration, infection, and limb loss. ${ }^{3}$ A study done in the UK highlighted, 18.5\% (14.2-22.7) of diabetic patients failed
Correspondence: Temesgen Mulugeta Institute of Health, School of Pharmacy, Department of Clinical Pharmacy, Jimma University, Jimma, Oromia, Ethiopia Tel +251917734764

Email temesgenmulugetaf@gmail.com 
to inspect their feet and $83 \%$ (79.1-86.9) did not have their feet measured when they last purchased shoes. Practices that put patients at risk included the use of direct forms of heat on the feet and walking barefoot. ${ }^{4}$ Bell et al reported, the foot self-care behaviors performed with the highest frequency of 6-7 days were washing the feet $(75.6 \%)$ and not soaking the feet $(79.2 \%)$. Conversely, $23 \%$ of the participants reported not checking their feet at all, and $54 \%$ did not inspect their shoes before wearing them. ${ }^{5}$

In developing countries, foot ulcers and amputations are unfortunately very common. Poverty, a lack of sanitation and hygiene, and barefoot walking often interact to compound the impact of diabetic foot damage. ${ }^{6}$ Wanja et al reported, among type 2 DM patients, the foot selfcare practice done correctly by most respondents were washing feet daily by $85 \%$ and not wearing high-heeled shoes ( $>2.5$ inches) by $81.1 \%$ while the worst performed practice was wearing sandals when performing outdoor activities where only $15.7 \%$ were likely to have the correct practice and $84.3 \%$ were likely to have the incorrect practice. ${ }^{7}$ Desalu et al reported $61.4 \%$ of the patients were unaware of the importance of inspecting the inside of the footwear for objects. Poor foot practices include; 89.2\% not receiving advice when they bought footwear and $88.6 \%$ failing to get appropriate size footwear. ${ }^{8}$

A meta-analysis result among Ethiopian diabetic patients showed $58 \%$ (95\% CI: $41-74 \%$ ) of the patients had a good level of foot-care practice. ${ }^{9}$ Seid and Isige reported, about $60.7 \%$ of the diabetic patients inspect their feet at least daily and $38.7 \%$ have never checked their shoes before they put them on. Also, 59.1\% and $69.3 \%$ of the patients never had a habit of drying their feet and between toes, respectively. The majority of the patients $(72.5 \%)$ reported never used the cream to moisturize their feet. About $66 \%$ of the patients cut toenails about once a month. The majority; $73.5 \%$ and $82.7 \%$ of the patients reported never walk barefoot in and outside the house, respectively. The majority of the patients $(84.7 \%)$ have never put their feet near the fire. ${ }^{10}$ Aklilu et al reported $80.2 \%$ of the patients inspected their feet regularly. However, only $31.0 \%$ of the patients inspect the inside of their footwear. The majority (94.1\%) of the patients do not walk barefoot regularly. ${ }^{11}$ Diabetic patients who had not practiced foot self-care were 2.52 times more likely to develop a diabetic foot ulcer. ${ }^{12}$

Diabetic patients and health care providers to diabetic patients should familiarize themselves with the principles of diabetic foot ulcer prevention. ${ }^{12}$ A paradigm shift is urgently needed to treat diabetic foot disease preventatively. ${ }^{6}$ Prevention of these ulcers is of paramount importance to reduce the patient and economic burden. ${ }^{2}$ Effective strategies for foot ulceration prevention include educating patients, their families, and healthcare workers about adequate foot care and regular foot examinations along with optimal glycemic control. Counseling patients regarding daily proper footwear and hygiene should be stressed during each clinic visit. ${ }^{13}$

Even though there are studies reporting foot self-care from different regions of Ethiopia, many of the reports were the numeric levels of foot self-care practice and associated socio-demographic and clinical factors; ${ }^{14-19}$ only two studies ${ }^{10,11}$ from the northern part of the country reported some elements of foot self-care practice. Identifying the specific elements of foot self-care will help clinicians to educate the patients about the foot selfcare comprehensively. There was no similar study from our referral and teaching Medical center which reported the patterns of foot self-care practice. Therefore, the aim of this study was to assess the patterns of foot self-care practice among diabetic patients attending a follow-up visit at the ambulatory clinic, Jimma Medical Center.

\section{Materials and Methods}

Study area and period: The study was conducted in Jimma Medical Center, Jimma, Oromia Region, Southwest Ethiopia between March 1 and April 5, 2019. Jimma Medical Center is located 352 kilometers away from the capital city of Ethiopia toward Southwest. The hospital provides service to 15 million people with 1600 staff members, 32 intensive care units, and 800 beds. ${ }^{20}$ The Hospital provides service for approximately 3000 diabetic patients every Monday and Tuesday. The services are mostly provided by intern doctors.

Study design: A hospital-based descriptive crosssectional study.

Source population: All diabetic patients attending follow-up at the ambulatory clinic of Jimma Medical Center.

Study population and selection: Diabetic patients aged greater than 18 years attending a follow-up visit during the data collection period at the ambulatory clinic of Jimma Medical Center were enrolled.

Exclusion criteria: Newly diagnosed DM patients $(\leq 1$ month duration), gestational diabetes, not volunteered to participate, and patients with the previous amputation above the ankle were excluded. 


\section{Sample Size and Sampling Technique Sample Size}

The sample size was determined using a single population proportion formula. Here, we used the proportion (p) from a previously published study done in Felege Hiwot Referral Hospital, Bahir Dar city, North West Ethiopia. ${ }^{10}$ According to this study, about $55.0 \%$ of the patients had good foot care practice with a $95 \%$ confidence interval (CI) and marginal error (d) of 5\%. $n=(z$ $\alpha / 2)^{2} \mathrm{p} \times(1-\mathrm{p}) / \mathrm{d}^{2}, \mathrm{n}=(1.96)^{2} \times 0.55 \times(1-0.55) /(0.05)^{2}$ $=380$. Since the source population was less than 10,000 , the sample size was adjusted using the correction formula to get a minimum sample size required for the study. And the total DM patients registered in the study hospital are 3000. Thus, the sample size was 337. Ten percent of the final sample size was added for nonrespondents $(\mathrm{nf}=337 \times 0.1+337 \approx 370)$. Therefore, the final sample size was 370 .

\section{Sampling Technique}

A consecutive sampling technique was used in which consecutive patients were interviewed until the required sample size was reached. To avoid double-counting of cases, the ID of the participants who had undergone the interview was documented each day and any patient coming to the clinic on a specific day was counter checked with the document before conducting the interview.

\section{Data Collection Techniques and Instrument}

The Diabetic foot self-care practice questionnaire was adapted from a validated instrument of Nottingham Assessment of Functional Foot care (NAFF). ${ }^{21}$ Fourteen items were selected out of 29. The rest of the questions were discharged after the pretest as they are inappropriate to measure the intended behavior in our context. The questionnaire was prepared in English and translated to the local language, Afan Oromo and Amharic, the translated version was again translated back to the English language to maintain the consistency in the meaning of words or concepts of the data collection tool. The Afan Oromo and Amharic versions were used for data collection. Data were collected through a face-to-face interview. The foot self-care practice among patients was responded to a set of practice questions of "always, often, sometimes, and rarely/never". Cronbach's alfa was calculated to check for the internal reliability of the 14 pretested items. Thus, Cronbach's alfa value was 0.65 .

\section{Data Quality Assurance}

A pretest was done before the actual data collection on the same population ( $10 \%$ of the final sample size) which did not include in the sample population. Correction and modification were made on the questionnaire before applied to the study depending on the result of the pretest. The data were checked for its completeness, accuracy, and consistency every day.

\section{Operational Definition}

In this study, the adequate practice of foot self-care by patients was according to the recommendation by the International Working Group on the Diabetic Foot (IWGDF) for the prevention of foot ulcers in diabetic patients. $^{2}$ Diabetic patients should inspect daily the entire surface of both feet and the inside of the shoes that will be worn; wash the feet daily (with careful drying, particularly between the toes); use emollients to lubricate dry skin; cut toenails straight across. Diabetic patients should not walk barefoot, in socks without shoes, or in thin-soled slippers, whether indoors or outdoors.

\section{Data Analysis}

The collected data were cleared, arranged, coded, checked for completeness, and then analyzed by SPSS version 20. The descriptive analysis was performed to summarize socio-demographic and other clinical data. The results were presented in means (SD), frequency, and percentage and narrated. Chi-square $\left(\chi^{2}\right)$ was used to compare the patients' previous information about diabetic foot and the history of diabetic foot ulcer between both sexes.

\section{Ethical Consideration}

Ethical clearance was obtained from the Institutional Review Board committee of Jimma University. The Ethical Review Board of Jimma University accepted and approved verbal informed consent. Verbal informed consent was obtained from the study participants to confirm their willingness for participation after explaining the objective of the study. Privacy and confidentiality of the patients' medical data were ensured during a patient interview by using code rather than their name. On top of this, participants were counseled about the proper foot care 
measures that should be taken into account in their daily life during the data collection period.

\section{Result}

\section{Socio-Demographic Characteristics}

Among 370 study participants, 207 (55.9\%) were males. The mean $( \pm \mathrm{SD})$ age was $(46.47 \pm 13.63)$. Most of the patients were Muslim followers 292 (78.9\%) and married 291 (78.6\%). One hundred forty-five (39.2\%) of the participants could not read and write. Regarding the occupational status of the respondents, 115 (31.1\%) were farmers. More than half of the patients lived in the urban area, 197 (53.2). Quarter 92 (24.9\%) of the respondents had a history of smoking (Table 1).

Table I Socio-Demographic Characteristics of Diabetic Patients on Follow-Up at Ambulatory Clinic, Jimma Medical Center, 2019

\begin{tabular}{|c|c|c|}
\hline \multicolumn{2}{|l|}{ Variables } & Frequency (\%) \\
\hline \multicolumn{3}{|c|}{ Age (Mean $\pm S D)$, years: $46.47 \pm \mid 3.63$} \\
\hline Sex & $\begin{array}{l}\text { Male } \\
\text { Female }\end{array}$ & $\begin{array}{l}207(55.9) \\
163(44.1)\end{array}$ \\
\hline Marital status & $\begin{array}{l}\text { Married } \\
\text { Unmarried } \\
\text { Divorced } \\
\text { Widowed }\end{array}$ & $\begin{array}{l}291(78.6) \\
44(11.9) \\
15(4.1) \\
20(5.4)\end{array}$ \\
\hline Religion & $\begin{array}{l}\text { Orthodox } \\
\text { Muslim } \\
\text { Protestant }\end{array}$ & $\begin{array}{l}57(I 5.4) \\
292(78.9) \\
21(5.7)\end{array}$ \\
\hline Educational status & $\begin{array}{l}\text { Cannot read and write } \\
\text { Can read and write } \\
\text { Grade I-8 } \\
\text { Grade } 9-12 \\
\text { College and above }\end{array}$ & $\begin{array}{l}145(39.2) \\
53(14.3) \\
75(20.3) \\
44(11.9) \\
53(14.3)\end{array}$ \\
\hline Occupational status & $\begin{array}{l}\text { Farmers } \\
\text { House wife } \\
\text { Private employee } \\
\text { Government employee } \\
\text { Unemployed } \\
\text { Student } \\
\text { Daily laborer }\end{array}$ & $\begin{array}{l}I I 5(31.1) \\
85(23) \\
48(13) \\
44(11.9) \\
30(8.1 \%) \\
24(6.5) \\
24(6.5)\end{array}$ \\
\hline Residence & $\begin{array}{l}\text { Urban } \\
\text { Rural }\end{array}$ & $\begin{array}{l}197(53.2) \\
173(46.8)\end{array}$ \\
\hline Habit of smoking & $\begin{array}{l}\text { Yes } \\
\text { No }\end{array}$ & $\begin{array}{l}92(24.9) \\
278(75.1)\end{array}$ \\
\hline
\end{tabular}

\section{Clinical Characteristics of Study}

\section{Participants}

Out of the 370 participants, $253(68.4 \%)$ of them were type two diabetes. Around half (48.6\%) of the patients had an illness duration of less than 5years. The majority of the respondents $(91.1 \%)$ had previous information about diabetic foot ulcer. Moreover, 132 (35.7\%) of the patients had a previous history of foot ulcer. There was no significant difference in the proportion between male and female patients in having information about diabetic foot ulcer and the history of foot ulcer $(\mathrm{P}>0.05)$ (Table 2).

\section{Diabetic Foot Self-Care Practices}

In this study, the practices of foot self-care were categorized into three domains.

\section{Foot Inspection}

The patients were asked how frequently they examine their feet, $73 \%$ of the patients were reported to inspect their foot more than once per day and $19.5 \%$ inspect their foot daily. However, regarding the inspection of their shoes before putting them on, $12.2 \%$ of the patients never check for objects impeded in their shoes (Table 3 )

\section{Foot Hygiene}

About half (48.4\%) and one-third (34.3\%) of patients wash their feet daily and more than once daily, respectively. And, $42.4 \%$ of the patients never dried between their foot toes after wash. Regarding the use of moisturizing cream, $63.5 \%$ of the patients never used a moisturizing cream on their feet to lubricate the dry skin. Among patients who practiced moisturizing, $26.5 \%$ of the patients

Table 2 Clinical Characteristics of Diabetes Patients on FollowUp at Ambulatory Clinic, Jimma Medical Center (JMC), in 2019

\begin{tabular}{|l|l|l|}
\hline \multicolumn{2}{|l|}{ Variables } & $\begin{array}{l}\text { Frequency } \\
\text { (\%) }\end{array}$ \\
\hline Type of DM & $\begin{array}{l}\text { Type I } \\
\text { Type 2 }\end{array}$ & $\begin{array}{l}117(31.6) \\
253(68.4)\end{array}$ \\
\hline Duration of DM & $<5$ years & $180(48.6)$ \\
& $5-10$ years & $137(37.0)$ \\
& $>10$ year & $53(14.3)$ \\
\hline Having previous information about & Yes & $337(91.1)$ \\
DFU & No & $33(8.90)$ \\
\hline Previous history of foot ulcer & Yes & $132(35.7)$ \\
& No & $238(64.3)$ \\
\hline
\end{tabular}

Abbreviations: DFU, diabetic foot ulcer; DM, diabetic mellitus. 
Table 3 Frequency Distribution of Patients' Response to Questions Related to Foot Self-Inspection and Foot Hygiene Among Diabetic Patients on Follow-Up in Ambulatory Clinic, Jimma Medical Center, 2019

\begin{tabular}{|c|c|c|c|c|}
\hline Practice Domains & Items & Response & Frequency & Percentage \\
\hline \multirow[t]{8}{*}{ Foot inspection } & \multirow[t]{4}{*}{ Examine (inspect) your feet } & More than once a day & 270 & $73.0 \%$ \\
\hline & & Once-daily & 72 & $19.5 \%$ \\
\hline & & 4-6 times weekly & 28 & $7.6 \%$ \\
\hline & & Once a week or less & 28 & $7.6 \%$ \\
\hline & \multirow[t]{4}{*}{ Check shoes before put them on } & Often & 204 & $55.1 \%$ \\
\hline & & Sometimes & 88 & $21.9 \%$ \\
\hline & & Rarely & 33 & $8.9 \%$ \\
\hline & & Never & 45 & $12.2 \%$ \\
\hline \multirow[t]{24}{*}{ Foot hygiene } & \multirow[t]{4}{*}{ Wash feet } & More than once daily & 127 & $34.3 \%$ \\
\hline & & Once-daily & 179 & $48.4 \%$ \\
\hline & & Most days a week & 45 & $12.2 \%$ \\
\hline & & Few days a week & 19 & $5.1 \%$ \\
\hline & \multirow[t]{4}{*}{ Feet dry after washing } & Often & 161 & 43.5 \\
\hline & & Sometimes & 42 & $11.4 \%$ \\
\hline & & Rarely & 48 & $13 \%$ \\
\hline & & Never & 119 & $32.2 \%$ \\
\hline & \multirow[t]{4}{*}{ Dry between feet toes after washing } & Always & 147 & $39.7 \%$ \\
\hline & & Often & 18 & $4.9 \%$ \\
\hline & & Sometimes & 48 & $13 \%$ \\
\hline & & Never & 157 & $42.4 \%$ \\
\hline & \multirow[t]{4}{*}{ Use moisturizing cream on feet } & Daily & 108 & $29.2 \%$ \\
\hline & & Once a week & 21 & $5.7 \%$ \\
\hline & & About once a month & 6 & $1.6 \%$ \\
\hline & & Never & 235 & $63.5 \%$ \\
\hline & \multirow[t]{4}{*}{ Put moisturizing cream between feet toes } & Daily & 98 & $26.5 \%$ \\
\hline & & Once a week & 26 & $7 \%$ \\
\hline & & About once a month & 4 & $1.1 \%$ \\
\hline & & Never & 242 & $65.4 \%$ \\
\hline & \multirow[t]{4}{*}{ Cut feet toe nail } & Once a week & 47 & $12.7 \%$ \\
\hline & & Once a month & 256 & $69.2 \%$ \\
\hline & & Less than once a month & 54 & $14.6 \%$ \\
\hline & & Never & 13 & $3.5 \%$ \\
\hline
\end{tabular}

put moisturizing cream between their feet toes daily. Twohundred fifty-six $(69.2 \%)$ of the patients cut their feet toe nails monthly (Table 3).

\section{Foot Self-Care Behaviors}

Ideally, patients were encouraged never to walk barefoot, in sandals/slippers, or in shoes without socks. In this study, $23.0 \%$ and $27.6 \%$ of the patients walk in sandals/slippers and shoes without socks most of the time, respectively. Only $27.3 \%$ of the patients changed their socks daily. Most of the patients never walk barefoot around (78.4\%) and outside (86.5\%) their house, respectively. And most of the patients never put their feet near the fire $(75.1 \%)$ (Table 4$)$.

\section{Discussion}

Patients with diabetes mellitus are at increased risk for pedal ulceration due to microvascular, neuropathic, and biomechanical changes to the foot. All patients with diabetes should receive education on proper diabetic foot care. Prevention of diabetic foot complications includes identifying the at-risk foot, daily exam and inspection, patient/family/healthcare provider education, appropriate shoe gear, and proper and early treatment of pre-ulcerative lesions. ${ }^{3}$ In this study, we 
Table 4 Frequency Distribution of Patients' Response to Questions Related to Foot Self-Care Behaviors Among Diabetic Patients on Follow-Up in Ambulatory Clinic, Jimma Medical Center

\begin{tabular}{|c|c|c|c|c|}
\hline \multirow[t]{6}{*}{$\begin{array}{l}\text { Foot self- } \\
\text { care } \\
\text { behaviors }\end{array}$} & $\begin{array}{l}\text { Walk in sandals/ } \\
\text { slippers }\end{array}$ & $\begin{array}{l}\text { Most of the } \\
\text { time } \\
\text { Sometimes } \\
\text { Rarely } \\
\text { Never }\end{array}$ & $\begin{array}{l}85 \\
118 \\
65 \\
102\end{array}$ & $\begin{array}{l}23.0 \% \\
31.9 \% \\
17.6 \% \\
27.6 \%\end{array}$ \\
\hline & $\begin{array}{l}\text { Walk in shoes } \\
\text { without socks }\end{array}$ & $\begin{array}{l}\text { Most of the } \\
\text { time } \\
\text { Sometimes } \\
\text { Rarely } \\
\text { Never }\end{array}$ & $\begin{array}{l}102 \\
68 \\
59 \\
141\end{array}$ & $\begin{array}{l}27.6 \% \\
18.4 \% \\
15.9 \% \\
38.1 \%\end{array}$ \\
\hline & Change socks & $\begin{array}{l}\text { More than } \\
\text { once a day } \\
\text { Everyday } \\
4-6 \text { times } \\
\text { a week } \\
\text { Less than } 4 \\
\text { times a week }\end{array}$ & $\begin{array}{l}9 \\
101 \\
99 \\
161\end{array}$ & $\begin{array}{l}2.4 \% \\
27.3 \% \\
26.8 \% \\
43.5 \%\end{array}$ \\
\hline & $\begin{array}{l}\text { Walk bare foot } \\
\text { around the house }\end{array}$ & $\begin{array}{l}\text { Often } \\
\text { Sometimes } \\
\text { Rarely } \\
\text { Never }\end{array}$ & $\begin{array}{l}21 \\
17 \\
42 \\
290\end{array}$ & $\begin{array}{l}5.7 \% \\
4.6 \% \\
11.4 \% \\
78.4 \%\end{array}$ \\
\hline & $\begin{array}{l}\text { Walk bare foot } \\
\text { outside the house }\end{array}$ & $\begin{array}{l}\text { Often } \\
\text { Sometimes } \\
\text { Rarely } \\
\text { Never }\end{array}$ & $\begin{array}{l}18 \\
5 \\
27 \\
320\end{array}$ & $\begin{array}{l}4.9 \% \\
1.4 \% \\
7.3 \% \\
86.5 \%\end{array}$ \\
\hline & $\begin{array}{l}\text { Put feet near the } \\
\text { fire }\end{array}$ & $\begin{array}{l}\text { Often } \\
\text { Sometimes } \\
\text { Rarely } \\
\text { Never }\end{array}$ & $\begin{array}{l}23 \\
29 \\
40 \\
278\end{array}$ & $\begin{array}{l}6.2 \% \\
7.8 \% \\
10.8 \% \\
75.1 \%\end{array}$ \\
\hline
\end{tabular}

assessed patterns of practice of foot self-care by diabetic patients on follow-up using the Nottingham Assessment of Functional Foot care tool. ${ }^{21}$

In this study, $35.7 \%$ of the diabetic patients on follow-up had a previous history of diabetic foot ulcer which is higher when compared to a study from North West Ethiopia, which reported $8.6 \%$ of the diabetic patients had a previous history of foot ulcer. ${ }^{18}$ This might be because $55.6 \%$ of the patients in a study from Northwest Ethiopia had a diabetic duration of less than 5 years compared to $48.6 \%$ of the patients in this study. In our study, $35.7 \%$ of the patients had a previous history of foot ulcer. This finding was higher compared to a study reported by Deribe and Woldemichael, where, $14.8 \%$ of the diabetic patients had a previous history of foot ulcer. ${ }^{15}$ This might be due to the most of the diabetic patients in a study by Deribe and Woldemichael were government and non-governmental employees compared to patients in this study, where most of them were farmers and illiterate. Moreover, $25 \%$ of the diabetic patients on follow-up had a history of/current smokers, which might the risk factor for the higher prevalence of a reported history of foot ulcer.

Regarding the frequency of inspection of their foot, $73 \%$ of patients were reported to inspect their foot more than once per day and $19.5 \%$ inspect their foot daily. The practice foot self-inspection in our study was higher when compared to a study by Seid and Isige, where $19.5 \%$ of the patients inspect their foot more than once daily and $41.2 \%$ inspect once daily. ${ }^{10}$ Desalu et al from Nigeria also reported, $40.9 \%$ of the patients inspected their foot regularly. ${ }^{8}$ However, our finding was comparable to a study by Aklilu et al. ${ }^{11}$ Having previous information about diabetic foot self-care might the reason for the discrepancy. In this study, $8.9 \%$ of the patients never had previous information about diabetic foot ulcer compared to $84.0 \%$ of the patients in the study by Seid and Isige. ${ }^{10}$

In this study, about $12 \%$ of the patients never check their shoes before putting them on for objects impeded in their shoes. Again, our finding was much lower when compared to $38.7 \%, 45.8 \%$ and $69.0 \%$ of the patients never inspect inside their footwear in the study by Seid and Isige ${ }^{10}$ and Dikeukwu ${ }^{22}$ Aklilu et al. ${ }^{11}$ This might be his might be because the majority of the patients (91.1\%) in this study had previous information about diabetic foot ulcer.

Concerning the frequency of foot wash, about half $(48.4 \%)$ of the patients wash their foot once daily and $34.3 \%$ of the patients wash more than once daily. Seid and Isige reported comparable findings, $49.5 \%$ wash their feet more than once a day followed by once a day which accounts for $44.1 \% .{ }^{10}$ However, our findings were lower when compared to a study from South Africa and Kenya, where $86.7 \%$ and $89.2 \%$ of the patients washed their feet once daily. ${ }^{22,23}$ This might be due to the patients included in both South Africa and Kenya studies were relatively elder adults. In our study, $32.2 \%$ of the diabetic patients never dry their feet after washing, which was lower compared to the report by Seid and Isige, where $59.1 \%$ of the patients reported never dry their feet after wash. ${ }^{10}$ This might be related to information differences related to foot care practice. Regarding the practice of drying between toes, $42.4 \%$ of the patients never had the habit of drying between their feet toes after wash. From Egypt, 33.6\% of the patients never dry between their toes after washing their feet. ${ }^{24}$ The difference might be related to the socio-economic and 
cultural differences between the two countries. Moreover, the patients from Egypt were more elders and had a longer disease duration compared to our patients.

Regarding the use of moisturizing cream for foot, $29.2 \%$ of the patients used a moisturizing cream on their feet daily. And $26.5 \%$ of the patients put moisturizing cream between their feet toes daily. However, Mbisi et al reported a higher number of patients $(63.3 \%)$ use a moisturizing cream on their feet daily and a few patients (5.4\%) use a moisturizing cream between their toes daily. ${ }^{23}$ This might be due to a few patients in Mbisi et al's study has an informal education (18.2\%) compared to this study where $39.2 \%$ of the patients cannot read and write.

Most of the patients (69.2\%) cut feet toenail once monthly. Eighty-five (23.0\%) of patients wear sandals/ slippers most of the time. Our finding was higher than a report by Mbisi et al, where $45.5 \%$ of the patients cut their toenail once monthly. Similarly, $1.7 \%$ of the patients were reported to wear slippers most of the time. ${ }^{23}$ The difference might be due to the age difference of patients between the studies, where most of the patients from the Kenyan study were elders.

Regarding the foot self-care behaviors, $38.1 \%$ of the patients never walk in shoes without socks. Wanja et al reported, relatively a lower number of patients $(27.6 \%)$ never wear shoes without socks. ${ }^{7}$ The difference might be related to the difference in residencies of the patients, where more than half $(53.2 \%)$ of the patients in our study came from Urban compared to the patients from Wanja et al were $62 \%$ of them were rural dwellers. Most of the patients responded never walk barefoot by $78.4 \%$ and $86.5 \%$ of the patients around and outside their house, respectively. This finding was relatively lower when compared to a report by Aklilu et al, where $94.1 \%$ of the patients did not walk barefoot regularly. ${ }^{11}$ Dikeukwu reported $75.0 \%$ of the diabetic patients reported not walking barefoot both in-home and outside. ${ }^{22}$ The difference in walking barefoot among diabetic patients might be due to the difference in the socioeconomic status between the populations.

The major limitations of this study are the authors did not assess the factors responsible for the patterns of practicing foot self-care and the recall bias by the patients/ respondents.

\section{Conclusion}

The practice of foot self-care by diabetic patients is not adequate. Patients were not adequately self-inspect and wash their foot at least daily, dry after wash and moisturize the dry skin. They walk barefoot, in sandals/slippers, and in shoes without socks. Therefore, clinicians should counsel every diabetic patient about the importance of foot selfinspection, foot hygiene, and the risk of walking barefoot, wearing sandals/slippers and shoes without socks at every follow-up visit.

\section{Abbreviations}

DM, diabetic mellitus; JMC, Jimma Medical Center; SD, standard deviation; DFU, diabetic foot ulcer.

\section{Data Sharing Statement}

The investigators will provide data upon reasonable request to the corresponding author.

\section{Ethics Approval and Consent to Participate}

Ethical clearance was obtained from the Ethical Review Board of Jimma University. The ethics approval was given in accordance with the Declaration of Helsinki. Patients were requested for verbal informed consent and confidentiality of the patients' data was maintained.

\section{Author Contributions}

All authors made substantial contributions to conception and design, acquisition of data, or analysis and interpretation of data; took part in drafting the article or revising it critically for important intellectual content; agreed to submit to the current journal; gave final approval of the version to be published; and agree to be accountable for all aspects of the work.

\section{Funding}

No funding was accepted for this manuscript.

\section{Disclosure}

The authors report no conflicts of interest for this work.

\section{References}

1. American Diabetes Association. Introduction: Standards of Medical Care in Diabetes. Vol. 43; 2020. Available from: https://care.diabetes journals.org/content/diacare/supp1/2019/12/20/43.Supplement_1.DC1/ Standards_of_Care_2020.pdf. Accessed November 23, 2020.

2. Bus SA, Lavery LA, Monteiro-Soares M, et al. IWGDF guideline on the prevention of foot ulcers in persons with diabetes. IWGDF Guidel. 2019:1-36.

3. Kayla Song AR, Chambers A. Diabetic Foot Care. StatPearls Publishing; 2020 doi:10.1080/00325481.1976.11708403

4. Pollock RD, Unwin NC, Connolly V. Knowledge and practice of foot care in people with diabetes. Diabetes Res Clin Pract. 2004;64 (2):117-122. doi:10.1016/j.diabres.2003.10.014 
5. Bell RA, Arcury TA, Snively BM, Smith SL, Stafford JM, Dohanish R. Diabetes foot self-care practices in a rural, triethnic population. Diabetes Educ. 2005;31(1):75-83. doi:10.1161/ CIRCULATIONAHA.110.956839

6. Ammar I, Jude E, Katia Langton FR, et al. International Diabetes Federation (IDF): Clinical Practice Recommendation on the Diabetic Foot: A Guide for Healthcare Professionals. Vol. 127; 2017. doi:10.1016/j.diabres.2017.04.013

7. Wanja L, Mwenda C, Mbugua R, Njau S. Determinants of foot self-care practices among diabetic patients attending diabetic clinic at a referral hospital, Meru County - Kenya. Int J Sci Res Public. 2019;9 (10):p9461. doi:10.29322/ijsrp.9.10.2019.p9461

8. Desalu OO, Salawu FK, Jimoh AK, Adekoya AO, Busari OA, Olokoba AB. Diabetic foot care: self reported knowledge and practice among patients attending three tertiary hospital in Nigeria. Ghana Med J. 2011;45(2):60-65. doi:10.4314/gmj.v45i2.68930

9. Ketema DB, Leshargie CT, Kibret GD, et al. Level of self-care practice among diabetic patients in Ethiopia: a systematic review and meta-analysis. BMC Public Health. 2020;20(1):1-12. doi:10.1186/s12889-020-8425-2

10. Seid A, Tsige Y. Knowledge, practice, and barriers of foot care among diabetic patients attending Felege Hiwot Referral Hospital, Bahir Dar, Northwest Ethiopia. Adv Nurs. 2015;2015:1-9. doi: $10.1155 / 2015 / 934623$

11. Aklilu T, Hiko D, Mohammed MA, Dekema NH. Diabetic patients' knowledge of their disease, therapeutic goals, and self-management: association with goal attainment at Dessie referral Hospital, Ethiopia. Ther Innov Regul Sci. 2014;48(5):583-591. doi:10.1177/ 2168479014524960

12. Iraj B, Khorvash F, Ebneshahidi A, Askari G. Prevention of diabetic foot ulcer. Int J Prev Med. 2013;4(3):373-376.

13. Priyadarshini J, Abdi S, Metwaly A, Al Lenjawi B, San Jose J, Mohamed H. Prevention of diabetic foot ulcers at primary care level. Dermatol Open J. 2018;3(1):4-9. doi:10.17140/drmtoj-3-129

14. Hailu E, Mariam WH, Belachew T, Birhanu Z. Self-care practice and glycaemic control amongst adults with diabetes at the jimma university specialized hospital in south-west Ethiopia: a cross-sectional study. African J Prim Heal Care Fam Med. 2012;4(1):1-6. doi:10.4102/phcfm.v4i1.311

15. Deribe B, Woldemichael K. Prevalence and factors influencing diabetic foot ulcer among diabetic patients attending Arbaminch Hospital, South Ethiopia. J Diabetes Metab. 2014;05(01):1-6. doi:10.4172/2155-6156.1000322
16. Gebrekirstos K, Solomon Gebrekiros AF. Prevalence and factors associated with diabetic foot ulcer among adult patients in Ayder Referral Hospital Diabetic Clinic Mekelle, North Ethiopia, 2013. J Diabetes Metab. 2015;06(08):2013-2016. doi:10.4172/21556156.1000579

17. Berhe KK, Gebru HB, Kahsay HB, Kahsay AA. Assessment of self care management and its associated factors among type 2 diabetes patients in Mekelle Hospital and Ayder Referral Hospitals, Mekelle City, Tigray, Northern Ethiopia, 2012/13. J Med Res Dis. 2017;17(1).

18. Mariam TG, Alemayehu A, Tesfaye E, et al. Prevalence of diabetic foot ulcer and associated factors among adult diabetic patients who attend the diabetic follow-up clinic at the University of Gondar Referral Hospital, North West Ethiopia, 2016: institutional-Based Cross-Sectional Study. J Diabetes Res. 2017;2017:1-8. doi:10.1155/ 2017/2879249

19. Dedefo MG, Ejeta BM, Wakjira GB, Mekonen GF, Labata BG. Self-care practices regarding diabetes among diabetic patients in West Ethiopia. BMC Res Notes. 2019;12(1):1-7. doi:10.1186/s13104-019-4258-4

20. Jimma University. Jimma University: specialized Hospital; 2015. Available from: https://www.ju.edu.et/?q=article/specializedhosptial. Accessed November 23, 2020.

21. Lincoln NB, Jeffcoate WJ, Ince P, Smith M, Radford KA. Validation of a new measure of protective footcare behaviour: the Nottingham Assessment of Functional Footcare (NAFF). Pract Diabetes Int. 2007;24(4):207-211. doi:10.1002/pdi.1099

22. Dikeukwu RA.The awareness and performance of appropriate foot self-care practices among diabetic patients attending Dr. Yusuf Dadoo Hospital, Gauteng Province, South Africa; 2011:76.

23. Mbisi AM, Gitonga LK, Kiruki S. Foot care practices among type 2 diabetics mellitus patients attending diabetes clinics in Embu County, Kenya. Open J Clin Diagn. 2019;09(04):126-144. doi:10.4236/ ojcd.2019.94009

24. Abu-elenin MM, Elshoura AA, Alghazaly GM. Knowledge, practice and barriers of foot self-care among diabetic patients at Tanta University Hospitals, Egypt. Egypt J Community Med. 2018;36 (4):94-102. doi:10.21608/ejcm.2018.23001

\section{Publish your work in this journal}

Diabetes, Metabolic Syndrome and Obesity: Targets and Therapy is an international, peer-reviewed open-access journal committed to the rapid publication of the latest laboratory and clinical findings in the fields of diabetes, metabolic syndrome and obesity research. Original research, review, case reports, hypothesis formation, expert opinion and commentaries are all considered for publication. The manuscript management system is completely online and includes a very quick and fair peer-review system, which is all easy to use. Visit http://www.dovepress.com/testimonials.php to read real quotes from published authors. 